\title{
Estrategia de implementación de la Ley de Autonomía Local de Andalucía y de la Ley de Participación de las entidades locales en los tributos de la Comunidad Autónoma de Andalucía en un contexto de crisis
}

\author{
Francisco de Paula Aguilera González
} Interventor General del Excmo. Ayuntamiento de Granada.

Sumario: I. INTRODUGGIÓN. II. CONTEXTO ECONÓMICO. III. CONTEXTO JURÍDICO. 1. Deuda Municipal. A. Porcentaje de deuda municipal en relación al resto de Administraciones. B. Régimen de las operaciones de crédito a largo plazo hasta la crisis. C. Evolución a partir de la crisis. 2. Déficit. 3. Planes de Saneamiento. III.4. Financiación Local. IV. ESTRATEGIA DE IMPLEMENTACIÓN DE LA LAULA y la LPTCA. 1. Estrategia de implementación de la LAULA. A. Competencias Impropias. B. Servicios e iniciativa económica local. C. Adaptación de las entidades instrumentales locales. D. Patrimonio de las entidades locales. E. Cooperación territorial y Demarcación municipal. 2. Estrategia de implementación de la LPTCA.

\section{RESUMEN:}

Las nuevas Corporaciones Locales salidas de las recientes elecciones locales de mayo de 2011, se enfrentan al reto de poner en marcha y aplicar la Ley 5/2010, de 11 junio, de Autonomía Local de Andalucía (LAULA) y la Ley 6/2010, de 11 de junio, reguladora de la participación de las entidades locales 
en los tributos de la Comunidad Autónoma de Andalucía (LPTCA), sumergidos en una de las mayores crisis económicas acaecidas desde la Gran Depresión de 1929.

En este artículo analizaremos el contexto económico-legislativo en el que se han aprobado y se van a implementar ambas leyes. Es necesario reflexionar cómo afrontar eficazmente la puesta en marcha de las mismas; cómo articular una estrategia útil para sacar el máximo partido posible a ambas leyes que van a afectar de forma decisiva a la gestión pública local de los próximos años.

Palabras clave: Autonomía, Financiación, Local, Andalucía.

\section{ABSTRACT:}

The new Local Authorities outputs recent local elections in May 2011, face the challenge of implementing and applying the Law 5 / 2010 of June 11, Local Self-Government of Andalusia (LAULA) and the Law 6 / 2010, of June 11 , regulating the participation of local taxes in the Autonomous Community of Andalusia (LPTCA), immersed in one of the biggest economic crisis since the Great Depression occurred in 1929.

This article explores the economic and legislative context in which they have adopted and will implement both laws. Need to think how to deal effectively with the implementation thereof; how to articulate a useful strategy to take full advantage both laws that will affect a decisive role in local governance in the coming years.

Keywords: Autonomy, Financing, Local, Andalucía.

\section{INTRODUCGIÓN}

Todos los que nos hemos acercado al estudio del municipalismo, sabemos que éste se sustenta en dos pilares básicos: la autonomía local y la suficiencia financiera. Ambos pilares han sido constitucionalizados en la Constitución Española de 1978: el artículo 137 que establece la autonomía local para la gestión de sus intereses; y el artículo 142 de suficiencia financiera: "Las Haciendas locales deberán disponer de los medios suficientes para el desempeño de las funciones que la Ley atribuye a las Corporaciones respectivas y se nutrirán fundamentalmente de tributos propios y de participación en los del Estado y de las Comunidades Autónomas." 
La Comunidad Autónoma de Andalucía en desarrollo de su Estatuto de Autonomía, reformado mediante Ley Orgánica 2/2007, de 19 de marzo, ha incidido sobre estos dos principios con la aprobación de la Ley 5/2010, de 11 junio, de Autonomía Local de Andalucía (LAULA) y de la Ley 6/2010, de 11 de junio, reguladora de la participación de las entidades locales en los tributos de la Comunidad Autónoma de Andalucía (LPTCA).

En el artículo que vamos a desarrollar analizaremos el contexto económico-legislativo en el que se han aprobado ambas leyes. Curiosamente, estando sumergidos en una de las mayores crisis económicas acaecidas desde la Gran Depresión de 1929, ninguna de las Exposiciones de Motivos de las dos leyes mencionan la realidad en la que se aprueban y entrarán en vigor.

Las nuevas Corporaciones Locales salidas de las recientes elecciones locales de mayo de 2011, se enfrentan al reto de poner en marcha y aplicar la LAULA, junto con el apoyo de la LPTCA, en un contexto social y económico nada favorable. En palabras de Antonio Torrero Mañas, Catedrático de Estructura Económica de la Universidad de Alcalá: "Sabemos cuándo prendió la mecha (agosto de 2007) pero no conocemos su duración, ni cuál va a ser su impacto socioeconómico, ni mucho menos sus resultados finales". En el momento actual, una recaída -una segunda recesión- es cada vez más probable, a juicio de economistas como Nouriel Roubini (Universidad de Nueva York), de historiadores económicos como Barry Eichengreen (de Berkeley) o de expertos europeos como Paul De Grauwe (Universidad de Lovaina) y Charles Wyplosz (Graduate Institute)"l.

Es necesario reflexionar cómo inciden y afectan estas dos leyes a nuestros Ayuntamientos y Entes Locales; cómo afrontar eficazmente la puesta en marcha de las mismas; cómo articular una estrategia útil para sacar el máximo partido posible a ambas leyes que van a afectar de forma decisiva a la gestión pública local de los próximos años. Todo un reto sobre el que conviene reflexionar.

\section{CONTEXTO ECONÓMICO}

En este apartado vamos a realizar un análisis estadístico, usando como fuente los datos publicados por el Ministerio de Economía y Hacienda, de la

\footnotetext{
${ }^{1}$ REPORTAJE: El agravamiento de la crisis - Las incertidumbres sobre la coyuntura mundial. Más dura será la recaída. La amenaza de segunda recesión planea sobre las grandes economías y sobre España. CLAUDI PÉREZ - Madrid - 11/09/2011 EL PAIS.
} 
evolución económica de los municipios andaluces durante los años que llevamos de crisis, para intentar apreciar en qué contexto económico se han aprobado la LAULA y la LPTCA.

Veamos en la Tabla 1 cuáles han sido los porcentajes de variación de los ingresos (derechos reconocidos netos) en el total de municipios de Andalucía desde el ejercicio 2006, antes del estallido de la crisis en agosto de 2007, hasta el ejercicio 2009, último del que se disponen datos completos.

Llama la atención en esta tabla el decrecimiento en un 54,29 \% de los ingresos por impuestos indirectos, Capítulo 2, motivado fundamentalmente por el derrumbe de los ingresos por la actividad constructiva, Impuesto sobre Construcciones, instalaciones y Obras, y el decrecimiento en un 8,84\% del Capítulo 3, Tasas y otros ingresos, posiblemente con la misma motivación, al estar en este capítulo integrados entre otros los ingresos por la Tasa de Licencia de Obras. Si bien es verdad que esta caída se ve compensada con el incremento de las liquidaciones por impuestos directos, Capítulo 1, y las transferencias corrientes otorgadas, Capítulo 4 . Todo esto hace que los ingresos por operaciones corrientes hayan crecido en este período un 10,66 \%.

Es también significativo el crecimiento de las transferencias de capital, Capítulo 7, un 172,51 \% por las subvenciones recibidas del Real Decreto-Ley 9/2008, de 28 de noviembre, por el que se crean un Fondo Estatal de Inversión Local y un Fondo Especial del Estado para la Dinamización de la Economía y el Empleo y se aprueban créditos extraordinarios para atender a su financiación. Y el incremento del endeudamiento reflejado en los derechos reconocidos en el Capítulo 9, con incremento del 31,27\%, muy probablemente motivado por las operaciones especiales de endeudamiento destinadas al pago a proveedores del Real Decreto-ley 5/2009, de 24 de abril, de medidas extraordinarias y urgentes para facilitar a las Entidades Locales el saneamiento de deudas pendientes de pago con empresas y autónomos. 
Tabla $n^{\circ} 1$ :

Liquidación de los Presupuestos de las Entidades locales 2006-2009

Presupuesto de Ingresos

Comunidad Autónoma de Andalucía

Total de Municipios

miles de euros

\begin{tabular}{|r|l|r|r|r|}
\hline \multirow{2}{*}{ Gap. } & \multicolumn{1}{|c|}{ Ingresos } & \multicolumn{2}{c|}{$\begin{array}{c}\text { Derechos } \\
\text { Neconocido } \\
\text { Netos }\end{array}$} \\
\hline & & $\mathbf{2 0 0 6}$ & $\mathbf{2 0 0 9}$ & VAR. \\
\hline $\mathbf{1}$ & Impuestos directos & 2.071 .683 & 2.602 .388 & $25,62 \%$ \\
\hline $\mathbf{2}$ & Impuestos indirectos & 520.637 & 238.007 & $-54,29 \%$ \\
\hline $\mathbf{3}$ & Tasas y otros ingresos & 1.558 .922 & 1.421 .037 & $-8,84 \%$ \\
\hline $\mathbf{4}$ & Transferencias corrientes & 2.087 .221 & 2.674 .183 & $28,12 \%$ \\
\hline $\mathbf{5}$ & Ingresos patrimoniales & 204.432 & 194.074 & $-5,07 \%$ \\
\hline & Operaciones Corrientes & $\mathbf{6 . 4 4 2 . 8 9 6}$ & $\mathbf{7 . 1 2 9 . 6 9 0}$ & $\mathbf{1 0 , 6 6 \%}$ \\
\hline $\mathbf{6}$ & $\begin{array}{l}\text { Enajenación de } \\
\text { inversiones reales }\end{array}$ & 591.761 & 122.292 & $-79,33 \%$ \\
\hline $\mathbf{7}$ & Transferencias de capital & 834.922 & 2.275 .215 & $172,51 \%$ \\
\hline & Operaciones de Capital & $\mathbf{1 . 4 2 6 . 6 8 3}$ & $\mathbf{2 . 3 9 7 . 5 0 8}$ & $\mathbf{6 8 , 0 5 \%}$ \\
\hline & $\begin{array}{l}\text { Operaciones no } \\
\text { Financieras }\end{array}$ & $\mathbf{7 . 8 6 9 . 5 7 9}$ & $\mathbf{9 . 5 2 7 . 1 9 8}$ & $\mathbf{2 1 , 0 6 \%}$ \\
\hline $\mathbf{8}$ & Activos financieros & 26.190 & 23.447 & $-10,47 \%$ \\
\hline $\mathbf{9}$ & Pasivos financieros & 663.060 & 870.367 & $31,27 \%$ \\
\hline & Operaciones Financieras & $\mathbf{6 8 9 . 2 5 1}$ & $\mathbf{8 9 3 . 8 1 4}$ & $\mathbf{2 9 , 6 8 \%}$ \\
\hline & Total ingresos & $\mathbf{8 . 5 5 8 . 8 3 0}$ & $\mathbf{1 0 . 4 2 1 . 0 1 1}$ & $\mathbf{2 1 , 7 6 \%}$ \\
\hline & & & & \\
\hline
\end{tabular}

Veamos ahora en la Tabla 2 cómo se han comportado los gastos en este período de 2006 a 2009. Es verdaderamente escandaloso el incremento de gasto del Capítulo 1, Gastos de personal, de un 26,33\%, cuando el IPG ha variado de diciembre de 2006 a diciembre de 2009 un 6,6\%. Este incremento se ha visto disminuido en el ejercicio 2010 con la aprobación del Real Decretoley 8/2010, de 20 de mayo, por el que se adoptan medidas extraordinarias para la reducción del déficit público, por el que se han reducido las retribuciones a los empleados públicos en un $5 \%$. El incremento del gasto en bienes corrientes y servicios, Capítulo 2, ha sido más moderado, un 14,25 \%, aunque superior al IPC. El del Capítulo 3, en un 33,82 \%, motivado por un alza de los 
intereses de las operaciones de crédito y por el aumento del endeudamiento. Y el del Capítulo 4, transferencias corrientes, un 33,03\%, sin que exista una explicación razonable, salvo que se trate de aportaciones a organismos autónomos y sociedades, que por motivos de la crisis hayan perdido ingresos. El total de gastos en operaciones corrientes ha crecido un $23,25 \%$.

$\mathrm{El}$ incremento en las inversiones reales, Capítulo 6, en un 126,30 \%, se debe al Fondo Estatal de Inversión Local. El decrecimiento en el Capítulo 9, Pasivos Financieros (amortizaciones de préstamos a largo plazo), un 29,91 \%, solo puede estar motivado por refinanciación de préstamos, puesto que el endeudamiento en este período lejos de bajar se incrementó.

Tabla $\mathrm{n}^{\circ} 2$ :

Liquidación de los Presupuestos de las Entidades locales 2006-2009

Presupuesto de Gastos

Comunidad Autónoma de Andalucía

Total de Municipios

miles de euros

\begin{tabular}{|r|l|r|r|r|}
\hline \multirow{2}{*}{ Gap. } & \multicolumn{1}{|c|}{ Gastos } & \multicolumn{2}{c|}{$\begin{array}{c}\text { Obligaciones } \\
\text { Reconocidas } \\
\text { Netas }\end{array}$} & \\
\hline & & $\mathbf{2 0 0 6}$ & $\mathbf{2 0 0 9}$ & VAR. \\
\hline $\mathbf{1}$ & Gastos de personal & 2.633 .069 & 3.326 .362 & $26,33 \%$ \\
\hline $\mathbf{2}$ & $\begin{array}{l}\text { Gastos en bienes } \\
\text { Corrientes y servicios }\end{array}$ & 1.916 .664 & 2.189 .864 & $14,25 \%$ \\
\hline $\mathbf{3}$ & Gastos financieros & 144.718 & 193.668 & $33,82 \%$ \\
\hline $\mathbf{4}$ & Transferencias corrientes & 775.856 & 1.032 .148 & $33,03 \%$ \\
\hline & Operaciones Corrientes & $\mathbf{5 . 4 7 0 . 3 0 7}$ & $\mathbf{6 . 7 4 2 . 0 4 3}$ & $\mathbf{2 3 , 2 5 \%}$ \\
\hline $\mathbf{6}$ & Inversiones reales & 1.813 .452 & 2.694 .715 & $48,60 \%$ \\
\hline $\mathbf{7}$ & Transferencias de capital & 187.614 & 201.007 & $7,14 \%$ \\
\hline & Operaciones de Capital & $\mathbf{2 . 0 0 1 . 0 6 5}$ & $\mathbf{2 . 8 9 5 . 7 2 1}$ & $\mathbf{4 4 , 7 1 \%}$ \\
\hline & Operaciones no & $\mathbf{7 . 4 7 1 . 3 7 3}$ & $\mathbf{9 . 6 3 7 . 7 6 4}$ & $\mathbf{2 9 , 0 0 \%}$ \\
\hline $\mathbf{8}$ & Financieras & 44.478 & 100.656 & $126,30 \%$ \\
\hline $\mathbf{9}$ & Pasivos financieros & 480.351 & 336.690 & $-29,91 \%$ \\
\hline & Operaciones Financieras & $\mathbf{5 2 4 . 8 2 9}$ & $\mathbf{4 3 7 . 3 4 6}$ & $\mathbf{- 1 6 , 6 7 \%}$ \\
\hline & Total gastos & $\mathbf{7 . 9 9 6 . 2 0 2}$ & $\mathbf{1 0 . 0 7 5 . 1 1 0}$ & $\mathbf{2 6 , 0 0 \%}$ \\
\hline
\end{tabular}


En la Tabla 3 analizamos el Ahorro Neto que se desprende de la ejecución de ingresos y gastos de las tablas anteriores, éste ha disminuido un 89,65\%, pero que si se calculara con la anualidad teórica de amortización real, incluyendo los préstamos en carencia, aún habría disminuido más.

Tabla $n^{\circ} 3$

\section{Liquidación de los Presupuestos de las Entidades locales 2006-2009 Evolución Ahorro Neto \\ Comunidad Autónoma de Andalucía Total de Municipios}

\begin{tabular}{|r|l|r|r|}
\hline & \multicolumn{1}{|c|}{$\mathbf{2 0 0 6}$} & $\mathbf{2 0 0 9}$ \\
\hline $\mathbf{+}$ & Derechos liquidados capítulo 1 a 5 & 6.442 .896 & 7.129 .690 \\
\hline $\mathbf{-}$ & $\begin{array}{l}\text { Obligaciones reconocidas } \\
\text { capítulos 1, 2 y 4 }\end{array}$ & 5.325 .589 & 6.548 .374 \\
\hline $\mathbf{-}$ & Suma capítulos 3 y 9 & 625.069 & 530.358 \\
\hline & AHORRO NETO & $\mathbf{4 9 2 . 2 3 8}$ & $\mathbf{5 0 . 9 5 7}$ \\
\hline
\end{tabular}

Como resumen de estas tres primeras tablas podemos decir que el problema de nuestros municipios se encuentra más del lado de los gastos, con un crecimiento de los gastos corrientes del 23,25 \% del 2006 al 2009, que del lado de los ingresos, al menos de los liquidados, con un incremento de los ingresos corrientes del 10,66 \%, lo que ha hecho disminuir el ahorro neto en un $89,65 \%$.

Por último, vamos a estudiar en la Tabla 4 como ha evolucionado el Remanente de Tesorería entre los años 2006 y 2008, último año del que tenemos datos de este concepto a través del Ministerio de Economía y Hacienda, pero nos da idea de cómo ha debido proseguir en los ejercicios siguientes.

El total de derechos pendientes de cobro se ha incrementado un 7,98 \% y el de obligaciones pendientes de pago un $13,14 \%$, disminuyendo las existencia en tesorería un 9,37 \%. El Remanente de Tesorería para Gastos generales, cuyo punto de partida en la liquidación del ejercicio 2006 ya era negativo, ha aumentado su déficit un 198,59 \%. Lo que nos da idea si extrapolamos cual puede ser el estado de las Haciendas Locales actualmente, teniendo en cuenta que la crisis lejos de superarse se ha agravado. 
Tabla $n^{\circ} 4$ :

Liquidación de los Presupuestos de las Entidades locales 2006-2008

Remanente de Tesorería

Comunidad Autónoma de Andalucía

Total de Municipios

miles de euros

\begin{tabular}{|c|c|c|c|}
\hline $\begin{array}{l}\text { Administración General más } \\
\text { Organismos Autónomos }\end{array}$ & 2006 & 2008 & VAR. \\
\hline 1.- Fondos líquidos & 2.124.342 & 1.925 .248 & $-9,37 \%$ \\
\hline $\begin{array}{l}\text { Derechos pendientes de cobro: } \\
\text { Del Presupuesto corriente }\end{array}$ & 1.763 .697 & 1.878 .935 & $6,53 \%$ \\
\hline De los Presupuestos cerrados & 3.081 .709 & 3.340 .207 & $8,39 \%$ \\
\hline De operaciones no presupuestarias & 174.871 & 207.184 & $18,48 \%$ \\
\hline $\begin{array}{l}\text { Menos ingresos pendientes de } \\
\text { aplicación definitiva }\end{array}$ & 442.286 & 482.896 & $9,18 \%$ \\
\hline 2.- Total Derechos pendientes de cobro & 4.577.992 & 4.943.431 & $7,98 \%$ \\
\hline $\begin{array}{l}\text { Obligaciones pendientes de pago: } \\
\text { Del Presupuesto corriente }\end{array}$ & 1.828 .685 & 1.955 .610 & $6,94 \%$ \\
\hline De los Presupuestos cerrados & 1.625 .993 & 2.046 .609 & $25,87 \%$ \\
\hline De operaciones no presupuestarias & 1.227 .884 & 1.385 .447 & $12,83 \%$ \\
\hline $\begin{array}{l}\text { Menos pagos realizados pendientes de } \\
\text { aplicación definitiva }\end{array}$ & 218.102 & 336.626 & $54,34 \%$ \\
\hline 3.- Total Obligaciones pendientes de pago & 4.464.460 & 5.051 .041 & $13,14 \%$ \\
\hline $\begin{array}{l}\text { I.- Total Remanente de Tesorería } \\
(1+2-3)\end{array}$ & 2.237 .873 & 1.817 .637 & $-18,78 \%$ \\
\hline II.- Saldos de dudoso cobro & 660.652 & 770.694 & $16,66 \%$ \\
\hline III.- Exceso de financiación afectada & 2.032 .911 & 2.407 .598 & $18,43 \%$ \\
\hline $\begin{array}{l}\text { IV.- Remanente de Tesorería para gastos } \\
\text { Generales (I - II - III) }\end{array}$ & -455.690 & -1.360 .655 & $198,59 \%$ \\
\hline
\end{tabular}




\section{CONTEXTO JURÍDICO}

\section{Deuda Municipal.}

A. Porcentaje de deuda municipal en relación al resto de Administraciones.

Es cierto que la crisis económica ha cogido a nuestros Ayuntamientos fuertemente endeudados si los consideramos individualmente, pero comparativamente con el resto de Administraciones Territoriales, Estado y Comunidades Autónomas, su endeudamiento es más bien pequeño y, sobre todo, está variando anualmente a un ritmo muy inferior, como vemos en la Tabla 5.

Tabla $n^{\circ} 5$ :

\section{DEUDA EN MILLONES DE EUROS A 31/03/2011 \\ Y VARIACIÓN INTERANUAL}

\begin{tabular}{|l|c|c|}
\hline & DEUDA & $\begin{array}{c}\text { VARIAGIÓN } \\
\text { ANUAL }\end{array}$ \\
\hline ADMINISTRAGIÓN GENTRAL & 521.007 & $+16,7 \%$ \\
\hline GOMUNIDADES AUTÓNOMAS & 121.729 & $+26,39 \%$ \\
\hline AYUNTAMIENTOS & 29.849 & $+1,3 \%$ \\
\hline $\begin{array}{l}\text { DIPUTACIONES, CONGEJOS Y } \\
\text { GABILDOS INSULARES }\end{array}$ & 7.194 & $+12,1 \%$ \\
\hline TOTAL ESPAÑA & 679.779 & $+17,4 \%$ \\
\hline
\end{tabular}

Fuente: Banco de España

B. Régimen de las operaciones de crédito a largo plazo hasta la crisis.

La legislación reguladora de la autorización de las operaciones de crédito a largo plazo de las Entidades locales ha sido bastante estable a lo largo del tiempo. A la entrada en vigor de la Ley 39/1988, de 28 de diciembre, reguladora de las Haciendas Locales, su artículo 54 requería la autorización de los órganos competentes del Ministerio de Economía y Hacienda, salvo que la Co- 
munidad Autónoma a que aquélla perteneciera tuviera atribuida en su Estatuto competencia en la materia, en cuyo caso correspondería a la misma, además de para las operaciones a formalizar con el exterior y las que se instrumentaran mediante emisiones de Deuda o cualquier otra apelación al crédito público (esta necesidad de autorización se ha mantenido vigente hasta la actualidad), cuando la cuantía de la operación proyectada rebasase el 5 por 100 de los recursos liquidados de la Entidad por operaciones corrientes, deducidos de la última liquidación presupuestaria practicada, salvo que el crédito se destinara a financiar obras y servicios incluidos en planes provinciales y programas de cooperación económica local debidamente aprobados y, en todo caso se necesitaba autorización, si la carga financiera anual derivada de la suma de las operaciones vigentes concertadas por la Entidad local y de la proyectada, excedía del 25 por 100 de los citados recursos. Esta redacción se mantuvo vigente hasta el 31 de diciembre de 1998.

La Ley 50/1998, de 30 de diciembre, de Medidas Fiscales, Administrativas y de Orden Social, en su artículo 59 modifica todo el Capítulo VII (operaciones de crédito) del Título I de la Ley 39/1988, de 28 de diciembre, Reguladora de las Haciendas Locales, necesitándose desde el 1 de enero de 1999 autorización cuando de los estados financieros que reflejen la liquidación de los Presupuestos, los resultados corrientes y los resultados de la actividad ordinaria del último ejercicio, se deduzca un ahorro neto negativo.

A estos efectos se entenderá por ahorro neto de las Entidades Locales y sus organismos autónomos de carácter administrativo la diferencia entre los derechos liquidados por los capítulos uno a cinco, ambos inclusive, del estado de ingresos, y de las obligaciones reconocidas por los capítulos uno, dos y cuatro del estado de gastos, minorada en el importe de una anualidad teórica de amortización de la operación proyectada y de cada uno de los préstamos y empréstitos propios y avalados a terceros pendientes de reembolso. No se incluirán en el cálculo de las anualidades teóricas, las operaciones de crédito garantizadas con hipotecas sobre bienes inmuebles, en proporción a la parte del préstamo afectado por dicha garantía.

Del mismo modo, precisan autorización las operaciones de crédito a largo plazo de cualquier naturaleza incluido el riesgo deducido de los avales, cuando el volumen total del capital vivo de las operaciones de crédito vigentes a corto y largo plazo exceda del 110 por 100 de los ingresos corrientes liquidados o devengados en el ejercicio inmediatamente anterior o, en su defecto, en el precedente a este último cuando el cómputo haya de realizarse en el primer semestre del año y no se haya liquidado el presupuesto correspondiente a 
aquél, según las cifras deducidas de los estados contables consolidados que integran los Presupuestos Generales de la Corporación.

El cálculo del porcentaje regulado en el párrafo anterior se realizará considerando las operaciones de crédito vigentes, tanto a corto como a largo plazo, valoradas con los mismos criterios utilizados para su inclusión en el balance. El riesgo derivado de los avales se computará aplicando el mismo criterio anterior a la operación avalada.

Cuando el ahorro neto sea de signo negativo, el Pleno de la respectiva Corporación deberá aprobar un plan de saneamiento financiero a realizar en un plazo no superior a tres años, en el que se adopten medidas de gestión, tributarias, financieras y presupuestarias que permitan como mínimo ajustar a cero el ahorro neto negativo de la entidad, organismo autónomo o sociedad mercantil. Dicho plan deberá ser presentado conjuntamente con la solicitud de la autorización correspondiente. No será precisa la presentación del plan de saneamiento financiero en el caso de autorización de operaciones de crédito que tengan por finalidad la sustitución de operaciones de crédito a largo plazo concertadas con anterioridad, en la forma prevista por la Ley, con el fin de disminuir la carga financiera o el riesgo de dichas operaciones, respecto a las obligaciones derivadas de aquéllas pendientes de vencimiento.

No obstante, las Entidades Locales de más de 200.000 habitantes podrán optar por sustituir las autorizaciones preceptuadas por la presentación de un Escenario de Consolidación Presupuestaria, para su aprobación por el órgano competente (Ministerio de Economía o Comunidad Autónoma). El escenario de consolidación presupuestaria contendrá el compromiso por parte de la Entidad local, aprobado por su Pleno, del límite máximo del déficit no financiero, e importe máximo del endeudamiento para cada uno de los tres ejercicios siguientes.

Con la Disposición Adicional Única de la Ley 18/2001, de 12 de diciembre, General de Estabilidad presupuestaria, con aplicación desde el 1 de enero de 2002, se añade un párrafo al apartado 7 a este artículo, para el otorgamiento de la autorización de las operaciones a que se refieren los apartados anteriores el órgano autorizante tendrá en cuenta, con carácter preferente, el cumplimiento del principio de estabilidad presupuestaria establecido en la Ley General de Estabilidad Presupuestaria.

Asimismo, se atenderá a la situación económica de la Entidad, Organismo autónomo o sociedad mercantil local peticionarios, deducida al menos de los análisis y de la información contable a la que se hace referencia en el apar- 
tado 1 de este artículo, incluido el cálculo del remanente de tesorería, del estado de previsión de movimientos y situación de la deuda y, además, el plazo de amortización de la operación, a la futura rentabilidad económica de la inversión a realizar y a las demás condiciones de todo tipo que conlleve el crédito a concertar o a modificar.

Manteniéndose vigente el núcleo del régimen de autorización de operaciones de crédito, conceptos de ahorro neto y 110 por ciento de volumen de capital vivo, que pasa al Real Decreto legislativo 2/2004, de 5 de marzo, Texto refundido de la Ley reguladora de las Haciendas Locales en su artículo 53 con la misma redacción, y está vigente en la actualidad.

La Ley 18/2001, de 12 de diciembre, General de Estabilidad presupuestaria, (hoy con el mismo contenido el Real Decreto Legislativo 2/2007, de 28 de diciembre, por el que se aprueba el texto refundido de la Ley General de Estabilidad Presupuestaria) en su artículo 23 regula cómo "el órgano autorizante tendrá en cuenta, con carácter preferente, el cumplimiento del principio de estabilidad presupuestaria establecido en la Ley General de Estabilidad Presupuestaria”. Estableciendo además la necesidad de que las Entidades Locales incluidas en el ámbito subjetivo definido en el artículo 111 del Texto Refundido de la Ley Reguladora de las Haciendas Locales, (capitales de provincia o comunidad autónoma o poblaciones de igual o más de 75.000 habitantes) que, incumpliendo el objetivo de estabilidad, tengan aprobado un plan económicofinanciero de reequilibrio deberán someter a autorización administrativa las operaciones de crédito a largo plazo que pretendan concertar.

Asimismo, estas entidades deberán solicitar autorización para concertar cualquier operación de endeudamiento, con independencia de su plazo, cuando no hayan presentado el plan económico-financiero o éste no hubiera sido aprobado por el Ministerio de Economía y Hacienda o, en su caso, por la comunidad autónoma correspondiente.

Las restantes entidades locales que incumplan el objetivo de estabilidad deberán solicitar autorización para concertar operaciones de crédito a largo plazo en los supuestos recogidos en los apartados 1 y 2 del artículo 53 del Texto Refundido de la Ley Reguladora de las Haciendas Locales, y expondrán, en la correspondiente solicitud, las medidas de corrección del desequilibrio presupuestario aprobadas.

Este artículo fue desarrollado por el artículo 25 del Real Decreto $1463 / 2007$, de 2 de noviembre, por el que se aprueba el reglamento de desa- 
rrollo de la Ley 18/2001, de 12 de diciembre, de Estabilidad Presupuestaria, en su aplicación a las entidades locales, que en su apartado 4 establece que el incumplimiento del objetivo de estabilidad en el último año de vigencia del plan, será causa suficiente de denegación de la autorización.

\section{Evolución a partir de la crisis.}

Si las Haciendas locales antes de la crisis de 2007 ya tenían un déficit estructural por el sostenimiento de competencias y servicios no propios, con la llegada de la misma éste se acentúa, actuando el Gobierno de España a través de regulaciones transitorias del endeudamiento local, sin que quede claro desde el principio cuál es el objetivo que se persigue.

1) En primer lugar, nos encontramos la aprobación de normas para posibilitar la concertación de operaciones especiales de endeudamiento destinadas al pago a proveedores, una primera con el Real Decreto-ley 5/2009, de 24 de abril, de medidas extraordinarias y urgentes para facilitar a las Entidades Locales el saneamiento de deudas pendientes de pago con empresas y autónomos, destinado a Las entidades locales que hayan liquidado sus presupuestos de 2008 con remanente de tesorería negativo, se haya generado el mismo en el propio ejercicio o proceda de la acumulación de remanentes negativos de ejercicios anteriores, o tengan obligaciones vencidas y exigibles pendientes de aplicar al presupuesto de 2008. Por cada entidad local, el importe máximo susceptible de financiación estará constituido por el saldo negativo del remanente de tesorería para gastos generales de 2008, por el importe, en su caso, de las obligaciones vencidas y exigibles que quedaron pendientes de aplicar al presupuesto, o por la suma de ambos. La operación de endeudamiento requerirá la aprobación por la Entidad Local de un plan de saneamiento que, por el mismo período de amortización de aquélla. El plazo de cancelación de esta operación de endeudamiento no podrá ser superior a seis años y con uno o dos años de carencia. Además, se establece una importante limitación al endeudamiento: La generación de remanente de tesorería negativo para gastos generales en el período de saneamiento, comportará la prohibición de realizar inversiones nuevas en el ejercicio siguiente financiadas con endeudamiento, sean éstas materiales, inmateriales o financieras, directas, o indirectas a través de subvenciones concedidas a entidades dependientes.

Y una segunda operación especial de endeudamiento con el Real Decreto-ley 8/2011, de 1 de julio, de medidas de apoyo a los deudores hipotecarios, de control del gasto público y cancelación de deudas con empresas y autónomos contraídas por las entidades locales, de fomento de la actividad empresa- 
rial e impulso de la rehabilitación y de simplificación administrativa, que habilita una línea de crédito con el Instituto de Crédito Oficial para la cancelación de deudas de las Entidades Locales con empresas y autónomos derivadas de la adquisición de suministros, realización de obras y prestación de servicios anteriores a 30 de abril de 2011. A los efectos anteriores, la línea financiera se diseña de forma que posibilite preferentemente la cancelación de las deudas con los autónomos y las pequeñas y medianas empresas, considerando así mismo la antigüedad de las certificaciones o documentos antes citados. El Importe de estas deudas, junto con los intereses estimados que la operación de crédito generaría, no podrá exceder, en ningún caso, el 25\% del importe anual de las entregas a cuenta de la participación de la entidad local en tributos del Estado del año 2011, una vez descontados los reintegros correspondientes a las liquidaciones definitivas de aquella participación del ejercicio 2008 y anteriores. El plazo de cancelación de las operaciones de endeudamiento no podrá ser superior a tres años ni éstas podrán concertarse con períodos de carencia, debiendo quedar cerrada el 31 de diciembre de 2014 la línea financiera que se ponga en marcha por el Instituto de Crédito Oficial, de acuerdo con el artículo 4 de este Real Decreto-Ley².

Del mismo modo que en el Real Decreto-ley 5/2009, el Real Decreto-ley 8/2011 establece una limitación al endeudamiento en su artículo 11: La generación de remanente de tesorería negativo para gastos generales en el período de amortización de las operaciones de endeudamiento comportará la prohibi-

\footnotetext{
${ }^{2}$ El origen del Real Decreto-ley 5/2009 fue la Ley 15/2010, de 5 de julio, de modificación de la Ley $3 / 2004$, de 29 de diciembre, por la que se establecen medidas de lucha contra la morosidad en las operaciones comerciales que en su D.A. $4^{\text {a }}$ dispuso: Nueva línea de crédito ICO-morosidad Entes Locales. El Gobierno, en el plazo de 30 días, a través del Instituto de Crédito Oficial, instrumentará una línea de crédito directa, en condiciones preferentes, dirigida a las Entidades Locales para facilitar el pago de deudas firmes e impagadas a empresas y autónomos con anterioridad al 30 de abril de 2010. La línea de crédito se cancelará y satisfará, caso por caso, siempre que no haya sido amortizada con carácter previo, en un plazo concertado con posterioridad a la entrada en vigor de la futura reforma del sistema de financiación de los Entes Locales y será instrumentada con independencia a los recursos provenientes de la PIE y vinculada a las obligaciones reconocidas a los proveedores del sector privado.

Posteriormente, la Ley PGE 2011 cambió la redacción de la D.A. mencionada, dándole esta redacción: El ICO, en su función de Agencia Financiera del Estado, continuará atendiendo las necesidades de financiación de las Comunidades Autónomas y Corporaciones Locales conforme a los criterios de riesgo económico, financiero y presupuestario propios de su actividad como entidad de crédito, estableciendo las garantías necesarias para la cobertura de las operaciones que pudieran ser financiadas por ICO; todo ello con absoluto respeto al principio de equilibrio financiero establecido en la Disposición Adicional Sexta del RD-L 12/1995, de 28 de diciembre. Asimismo, las relaciones financieras entabladas entre el ICO y las citadas Administraciones Públicas deberán ser coherentes con el proceso de consolidación fiscal para garantizar la sostenibilidad de las finanzas públicas a medio plazo, conforme a los objetivos de los Presupuestos Generales del Estado para el año 2011.
} 
ción de realizar inversiones nuevas en el ejercicio siguiente financiadas con endeudamiento, sean éstas materiales, inmateriales o financieras, directas, o indirectas a través de subvenciones concedidas a entidades dependientes.

2) En segundo lugar, se varía transitoriamente el régimen de autorización de las operaciones de crédito a largo plazo. Así la Ley 26/2009, de 23 de diciembre, de Presupuestos Generales del Estado para el año 2010, en su D.A. $46^{a}$ establece que con carácter excepcional y exclusivamente para el año 2010, y hasta que se apruebe la reforma de la Ley Reguladora de las Haciendas Locales, se eleva del 110 al $125 \%$ el porcentaje establecido en el artículo 53.2 del Texto Refundido de la Ley Reguladora de las Haciendas Locales, aprobado por el Real Decreto Legislativo 2/2004, de 5 de marzo, a efectos de determinar los supuestos en los que, por su nivel de endeudamiento, las Entidades locales deberán solicitar autorización para concertar operaciones de crédito a largo plazo a los órganos competentes del Ministerio de Economía y Hacienda o de la Comunidad Autónoma respectiva en el caso de que tenga atribuida en su Estatuto de Autonomía competencia en esta materia.

Poco después el Real Decreto-ley 8/2010, de 20 de mayo, por el que se adoptan medidas extraordinarias para la reducción del déficit público (BOE de 24 de mayo de 2010), en su artículo 14.Dos. regula que a partir de la entrada en vigor de la presente norma y hasta 31 de diciembre de 2011, las entidades locales y sus entidades dependientes clasificadas en el sector Administraciones Públicas no podrán acudir al crédito público o privado a largo plazo, en cualquiera de sus modalidades, para la financiación de sus inversiones, ni sustituir total o parcialmente operaciones preexistentes, a excepción de aquellas que en términos de valor actual neto resulten beneficiosas para la entidad por disminuir la carga financiera, el plazo de amortización o ambos. Pero en los dos días siguientes se publican sendas correcciones de errores y en la primera de ellas (BOE 25 de mayo) se corrige el siguiente error: - En la página 45121, artículo 14. Dos, donde dice: «A partir de la entrada en vigor de la presente norma y hasta 31 de diciembre de $2011 \ldots$, debe decir: "A partir del 1 de enero de 2011 y hasta 31 de diciembre de $2011 \ldots$.

Pero se aprueba la Ley 39/2010, de 22 de diciembre, de Presupuestos Generales del Estado para el año 2011 y en la DF $15^{\mathrm{a}}$ se modifica el Real Decreto-ley 8/2010, de 20 de mayo, por el que se adoptan medidas extraordinarias para la reducción del déficit público en su artículo 14.Dos que queda redactado de la siguiente manera: Dos. En el ejercicio económico 2011, las entidades locales y sus entidades dependientes clasificadas en el sector Administraciones Públicas que liquiden el ejercicio 2010 con ahorro neto positivo, 
calculado en la forma que establece el artículo 53 del Texto Refundido de la Ley reguladora de las Haciendas Locales aprobado por Real Decreto Legislativo $2 / 2004$, de 5 de marzo, podrán concertar nuevas operaciones de crédito a largo plazo para la financiación de inversiones, cuando el volumen total del capital vivo no exceda del $75 \%$ de los ingresos corrientes liquidados o devengados, según las cifras deducidas de los estados contables consolidados, con sujeción, en su caso, al Texto Refundido de la Ley Reguladora de las Haciendas Locales y a la Normativa de Estabilidad Presupuestaria. A efectos del cálculo del capital vivo se tendrán en cuenta todas las operaciones vigentes a 31 de diciembre de 2010, incluido el riesgo deducido de avales e incrementado, en su caso, en los saldos de operaciones formalizadas no dispuestos y en el importe de la operación u operaciones proyectadas en 2011. Las entidades que no cumplan los requisitos anteriores no podrán concertar en 2011 operaciones de crédito a largo plazo.

3) En tercer lugar, con el artículo 14.Tres del Real Decreto-ley 8/2010, de 20 de mayo, por el que se adoptan medidas extraordinarias para la reducción del déficit público se cambia el régimen de las operaciones a corto plazo o de tesorería. Las operaciones a corto plazo concertadas para cubrir situaciones transitorias de financiación reguladas en el artículo 51 del Texto Refundido de la Ley Reguladora de las Haciendas Locales deberán quedar canceladas a 31 de diciembre de cada año. Recordar que se trata de operaciones extrapresupuestarias y que no influyen en el cálculo de la estabilidad presupuestaria.

\section{Déficit}

El concepto de déficit financiero de las entidades locales medido como inestabilidad presupuestaria surge a partir de la Ley 18/2001, de 12 de diciembre, General de Estabilidad presupuestaria, (hoy con el mismo contenido Real Decreto Legislativo 2/2007, de 28 de diciembre, por el que se aprueba el texto refundido de la Ley General de Estabilidad Presupuestaria) y el Real Decreto 1463/2007, de 2 de noviembre, por el que se aprueba el reglamento de desarrollo de la Ley 18/2001, de 12 de diciembre, de Estabilidad Presupuestaria, ya en período de crisis económica se han aprobado otras normas con el mismo objetivo.

1) La Ley 2/2011, de 4 de marzo, de Economía Sostenible que en su artículo 32 establece el principio de sostenibilidad presupuestaria de las Administraciones Públicas. Todas las Administraciones Públicas deben contribuir al logro de la sostenibilidad presupuestaria de las finanzas públicas, entendida co- 
mo la capacidad para financiar los compromisos de gasto presentes y futuros. Para garantizar la sostenibilidad presupuestaria, las Administraciones Públicas aplicarán una política de racionalización y contención del gasto y se adecuarán a los principios de estabilidad presupuestaria, transparencia, plurianualidad y eficacia, en los términos definidos en la normativa de estabilidad presupuestaria. Las disposiciones legales y reglamentarias, los actos administrativos, los contratos y los convenios de colaboración y cualquier otra actuación de las Administraciones Públicas deberán valorar sus repercusiones y efectos, de forma que se garantice este principio. Todo gasto se evaluará atendiendo a los principios de eficiencia y simplificación de los servicios prestados, incentivando la productividad del sector público. En especial, el Estado promoverá la colaboración entre las Administraciones Públicas para mejorar la eficiencia en la prestación de servicios públicos.

No debemos dejar de mencionar que en esta misma Ley de Economía Sostenible en su artículo 36 se sanciona el incumplimiento por las Entidades locales de la obligación de remitir la información relativa a la liquidación de sus presupuestos a la Administración General del Estado con la retención a partir del mes de septiembre del ejercicio siguiente al que corresponda aquella liquidación, y hasta que se produzca la citada remisión, el importe de las entregas mensuales a cuenta de la participación en los tributos del Estado que les corresponda. Aquellas Entidades locales que justifiquen razonadamente la imposibilidad material de dar cumplimiento a la obligación mencionada en el apartado anterior, la Dirección General de Coordinación Financiera con las Comunidades Autónomas y con las Entidades locales suspenderá por el tiempo que determine, de acuerdo con aquellas alegaciones, la retención de fondos a la que se refiere dicho apartado, previa solicitud del Pleno de la Entidad local afectada.

2) Recientemente las Cortes Generales han aprobado la reforma del artículo 135 de la Constitución Española, que por su importancia transcribo en texto íntegro:

\section{"Exposición de motivos.}

Más de treinta años después de la entrada en vigor de la Constitución, formando parte España de la Unión Económica y Monetaria Europea, que consolida y proyecta sus competencias en el marco de una creciente gobernanza común, y siendo cada vez más evidentes las repercusiones de la globalización económica y financiera, la estabilidad presupuestaria adquiere un valor verdaderamente estructural y condicionante de la capacidad de actuación del Estado, del mantenimiento y desarrollo del Estado Social que proclama el artículo 1.1 de la propia Ley Fundamentaly, en definitiva, de la prosperidad presente y futura de los ciudadanos. Un valor, pues, que justifica su consagración cons- 
titucional, con el efecto de limitar y orientar, con el mayor rango normativo, la actuación de los poderes públicos.

Para llegar hasta aquí, la salvaguarda de la estabilidad presupuestaria ya supuso un instrumento imprescindible para lograr la consolidación fiscal que nos permitió acceder a la Unión Económica y Monetaria y fue posteriormente recogida en normas de rango legislativo.

En el mismo sentido, el Pacto de Estabilidad y Crecimiento tiene como finalidad prevenir la aparición de un déficit presupuestario excesivo en la zona euro, dando así confianza en la estabilidad económica de dicha zona y garantizando una convergencia sostenida y duradera de las economías de los Estados Miembros.

La actual situación económica y financiera, marcada por una profunda y prolongada crisis, no ha hecho sino reforzar la conveniencia de llevar el principio de referencia a nuestra Constitución, al objeto de fortalecer la confianza en la estabilidad de la economía española a medio y largo plazo.

La presente reforma del artículo 135 de la Constitución Española persigue, por tanto, garantizar el principio de estabilidad presupuestaria, vinculando a todas las Administraciones Públicas en su consecución, reforzar el compromiso de España con la Unión Europea y, al mismo tiempo, garantizar la sostenibilidad económica y social de nuestro país.

Artículo único.

El artículo 135 de la Constitución Española queda redactado como sigue:

«1. Todas las Administraciones Públicas adecuarán sus actuaciones al principio de estabilidad presupuestaria.

2. El Estado y las Comunidades Autónomas no podrán incurrir en un déficit estructural que supere los márgenes establecidos, en su caso, por la Unión Europea para sus Estados Miembros.

Una Ley Orgánica fijará el déficit estructural máximo permitido al Estado y a las Comunidades Autónomas, en relación con su producto interior bruto. Las Entidades Locales deberán presentar equilibrio presupuestario.

3. El Estado y las Comunidades Autónomas habrán de estar autorizados por Ley para emitir deuda pública o contraer crédito.

Los créditos para satisfacer los intereses y el capital de la deuda pública de las Administraciones se entenderán siempre incluidos en el estado de gastos de sus presupuestos y su pago gozará de prioridad absoluta.

Estos créditos no podrán ser objeto de enmienda o modificación, mientras se ajusten a las condiciones de la Ley de emisión.

El volumen de deuda pública del conjunto de las Administraciones Públicas en relación al producto interior bruto del Estado no podrá superar el valor de referencia establecido en el Tratado de Funcionamiento de la Unión Europea.

4. Los límites de déficit estructural y de volumen de deuda pública sólo podrán superarse en caso de catástrofes naturales, recesión económica o situaciones de emergencia extraordinaria que escapen al control del Estado y perjudiquen considerablemente la situación financiera o la sostenibilidad económica o social del Estado, apreciadas por la mayoría absoluta de los miembros del Congreso de los Diputados.

5. Una Ley Orgánica desarrollará los principios a que se refiere este artículo, así como la participación, en los procedimientos respectivos, de los órganos de coordinación institucional entre las Administraciones Públicas en materia de política fiscal y financiera. En todo caso, regulará:

a) La distribución de los límites de déficit y de deuda entre las distintas Administraciones Pú- 
blicas, los supuestos excepcionales de superación de los mismos y la forma y plazo de corrección de las desviaciones que sobre uno y otro pudieran producirse.

b) La metodología y el procedimiento para el cálculo del déficit estructural.

c) La responsabilidad de cada Administración Pública en caso de incumplimiento de los objetivos de estabilidad presupuestaria.

6. Las Comunidades Autónomas, de acuerdo con sus respectivos Estatutos y dentro de los límites a que se refiere este artículo, adoptarán las disposiciones que procedan para la aplicación efectiva del principio de estabilidad en sus normas y decisiones presupuestarias».

Disposición adicional única.

1. La Ley Orgánica prevista en el artículo 135 de la Constitución Española deberá estar aprobada antes de 30 de junio de 2012.

2. Dicha Ley contemplará los mecanismos que permitan el cumplimiento del límite de deuda a que se refiere el artículo 135.3.

3. Los límites de déficit estructural establecidos en el 135.2 de la Constitución Española entrarán en vigor a partir de 2020.

Disposición final única.

La presente reforma del artículo 135 de la Constitución Española entrará en vigor el mismo día de la publicación de su texto oficial en el «Boletín Oficial del Estado». Se publicará también en las demás lenguas de España".

Resaltemos de esta reforma lo dispuesto para las entidades locales. Éstas deberán presentar, en todos los casos, equilibrio presupuestario. Una Ley Orgánica regulará la responsabilidad de las entidades locales en caso de incumplimiento de los objetivos de estabilidad presupuestaria.

\section{Financiación}

1) A los problemas para el acceso al crédito por las entidades locales que han supuesto todas las modificaciones legislativas ya estudiadas se ha sumado que las liquidaciones definitivas de la participación en tributos del Estado de los ejercicios 2008 y 2009 han sido muy negativas, al haberse recibido anticipos a cuenta por un importe calculado por el Ministerio de Economía y Hacienda muy superior al real al final del ejercicio. Las Leyes de Presupuestos de los sucesivos ejercicios han dispuesto su devolución diferida en el tiempo.

La Ley 26/2009, de 23 de diciembre, de Presupuestos Generales del Estado para el año 2010 en su artículo 91 regula que los saldos deudores que se pudieran derivar de la liquidación definitiva de la participación en tributos del Estado del ejercicio 2008, serán reembolsados por las Entidades Locales afectadas mediante compensación con cargo a las entregas a cuenta que, por cualquier concepto del sistema de financiación, se perciban a partir de enero de 2011, en 60 mensualidades. 
Del mismo modo la Ley 39/2010, de 22 de diciembre, de Presupuestos Generales del Estado para el año 2011 en su artículo 99, respecto de los saldos deudores que se pudieran derivar de la liquidación del ejercicio 2009 que, serán reembolsados por las Entidades Locales afectadas mediante compensación con cargo a las entregas a cuenta que, por cualquier concepto del sistema de financiación, se perciban a partir de enero de 2012, en 60 mensualidades.

En el año 2012 se acumularán los descuentos por las liquidaciones definitivas de los años 2008 y 2009.

Además, reseñar que computan como endeudamiento financiero ${ }^{3}$.

2) Por último, hacer mención a la Ley $15 / 2010$, de 5 de julio, de modificación de la Ley $3 / 2004$, de 29 de diciembre, por la que se establecen medidas de lucha contra la morosidad en las operaciones comerciales, que modifica el apartado 4 del artículo 200 de la Ley de Contratos del Sector Público que pasa a tener la siguiente redacción:

"4. La Administración tendrá la obligación de abonar el precio dentro de los treinta días siguientes a la fecha de la expedición de las certificaciones de obras o de los correspondientes documentos que acrediten la realización total o parcial del contrato, sin perjuicio del plazo especial establecido en el artículo 205.4, y, si se demorase, deberá abonar al contratista, a partir del cumplimiento de dicho plazo de treinta días, los intereses de demora y la indemnización por los costes de cobro en los términos previstos en la Ley 3/2004, de 29 de diciembre, por la que se establecen medidas de lucha contra la morosidad en las operaciones comerciales. Cuando no proceda la expedición de certificación de obra y la fecha de recibo de la factura o solicitud de pago equivalente se preste a duda o sea anterior a la recepción de las mercancías o a la prestación de los servicios, el plazo de treinta días se contará desde dicha fecha de recepción o prestación”.

El plazo de pago de 30 días se alcanzará durante un período transitorio que finaliza el 31 de diciembre de 2012 (D.T. $8^{\text {a }}$ a la LCSP).

Y se añade un nuevo artículo 200 bis redactado del siguiente modo: Públicas.

"Artículo 200 bis. Procedimiento para hacer efectivas las deudas de las Administraciones

Transcurrido el plazo a que se refiere el artículo 200.4 de esta Ley, los contratistas podrán reclamar por escrito a la Administración contratante el cumplimiento de la obligación de pago y, en su

\footnotetext{
${ }^{3}$ Nota Informativa $n^{\circ} 1 / 2010$ de la IGAE: "Registro contable de las cantidades a devolver por las entidades locales como consecuencia de la liquidación definitiva de la participación en los tributos del Estado del ejercicio 2008"
} 
caso, de los intereses de demora. Si, transcurrido el plazo de un mes, la Administración no hubiera contestado, se entenderá reconocido el vencimiento del plazo de pago y los interesados podrán formular recurso contencioso-administrativo contra la inactividad de la Administración, pudiendo solicitar como medida cautelar el pago inmediato de la deuda. El órgano judicial adoptará la medida cautelar, salvo que la Administración acredite que no concurren las circunstancias que justifican el pago o que la cuantía reclamada no corresponde a la que es exigible, en cuyo caso la medida cautelar se limitará a esta última. La sentencia condenará en costas a la Administración demandada en el caso de estimación total de la pretensión de cobro".

En esta misma Ley 15/2010, en su artículo 4 se establece que los Tesoreros o, en su defecto, Interventores de las Corporaciones locales elaborarán trimestralmente un informe sobre el cumplimiento de los plazos previstos en esta Ley para el pago de las obligaciones de cada Entidad local, que incluirá necesariamente el número y cuantía global de las obligaciones pendientes en las que se esté incumpliendo el plazo. Sin perjuicio de su posible presentación y debate en el Pleno de la Corporación local, dicho informe deberá remitirse, en todo caso, a los órganos competentes del Ministerio de Economía y Hacienda y, en su respectivo ámbito territorial, a los de las Comunidades Autónomas que, con arreglo a sus respectivos Estatutos de Autonomía, tengan atribuida la tutela financiera de las Entidades locales. Tales órganos podrán igualmente requerir la remisión de los citados informes.

Y que la Intervención u órgano de la Entidad local que tenga atribuida la función de contabilidad incorporará al informe trimestral al Pleno, una relación de las facturas o documentos justificativos con respecto a los cuales hayan transcurrido más de tres meses desde su anotación en el registro de facturas y no se hayan tramitado los correspondientes expedientes de reconocimiento de la obligación o se haya justificado por el órgano gestor la ausencia de tramitación de los mismos. El Pleno, en el plazo de 15 días contados desde el día de la reunión en la que tenga conocimiento de dicha información, publicará un informe agregado de la relación de facturas y documentos que se le hayan presentado agrupándolos según su estado de tramitación.

\section{Planes de Saneamiento}

En apartados anteriores ya hemos hecho mención a la existencia de los "Planes de Saneamiento" regulados en varias Leyes.

1) En el artículo 53 del Real Decreto legislativo 2/2004, de 5 de marzo, Texto refundido de la Ley reguladora de las Haciendas Locales. Cuando el ahorro neto sea de signo negativo, el Pleno de la respectiva Corporación deberá aprobar un plan de saneamiento financiero a realizar en un plazo no su- 
perior a tres años, en el que se adopten medidas de gestión, tributarias, financieras y presupuestarias que permitan como mínimo ajustar a cero el ahorro neto negativo de la entidad, organismo autónomo o sociedad mercantil. Dicho plan deberá ser presentado conjuntamente con la solicitud de la autorización correspondiente. No será precisa la presentación del plan de saneamiento financiero en el caso de autorización de operaciones de crédito que tengan por finalidad la sustitución de operaciones de crédito a largo plazo concertadas con anterioridad, en la forma prevista por la Ley, con el fin de disminuir la carga financiera o el riesgo de dichas operaciones, respecto a las obligaciones derivadas de aquéllas pendientes de vencimiento.

2) En el artículo 22 del Real Decreto Legislativo 2/2007, de 28 de diciembre, por el que se aprueba el texto refundido de la Ley General de Estabilidad Presupuestaria para corrección de las situaciones de incumplimiento del objetivo de estabilidad. Las entidades locales que no hayan cumplido el objetivo de estabilidad vendrán obligadas a la aprobación por el Pleno de la Corporación en el plazo de tres meses desde la aprobación o liquidación del Presupuesto o aprobación de la Cuenta General en situación de desequilibrio, de un plan económico-financiero de reequilibrio a un plazo máximo de tres años. En este plan se recogerán las actividades a realizar y las medidas a adoptar en relación con la regulación, ejecución y gestión de los gastos y de los ingresos, que permitan garantizar el retorno a una situación de estabilidad presupuestaria. En el caso de las entidades locales incluidas en el ámbito subjetivo definido en el artículo 111 del Texto Refundido de la Ley Reguladora de las Haciendas Locales, el plan económico-financiero de reequilibrio será remitido para su aprobación al Ministerio de Economía y Hacienda, que, además, será el órgano responsable de su seguimiento, salvo en el supuesto de que la comunidad autónoma en cuyo territorio se encuentre la entidad local tenga atribuida en su Estatuto de Autonomía la competencia de tutela financiera sobre las entidades locales. En este último supuesto el plan económico-financiero será remitido a la correspondiente comunidad autónoma, la cual será la responsable de su aprobación y seguimiento. La comunidad autónoma concernida deberá remitir información al Ministerio de Economía y Hacienda de dichos planes y de los resultados del seguimiento que efectúe sobre los mismos. Los planes económico-financieros de reequilibrio se remitirán para su conocimiento a la Comisión Nacional de Administración Local. Se dará a estos planes la misma publicidad, a efectos exclusivamente informativos, que la establecida por las leyes para los Presupuestos de la entidad.

La compatibilidad entre el plan de saneamiento financiero del artículo 53 de la Ley de Haciendas Locales y el Plan económico- financiero de reequilibrio 
del artículo 22 de la Ley General de Estabilidad Presupuestaria se establece en el artículo 25.2 del Reglamento de desarrollo de la Ley General de Estabilidad presupuestaria. Si el informe de evaluación es de incumplimiento en alguno de los dos ejercicios, el anterior o el corriente, además de la información anterior, la solicitud deberá incorporar el plan económico-financiero aprobado por el Pleno, compatible con las medidas de saneamiento que procedan para corregir el remanente de tesorería para gastos generales o el ahorro neto cuando resulten negativos, si se diera alguno o los dos supuestos, en los términos establecidos para cada uno de los casos en el texto refundido de la Ley reguladora de las Haciendas Locales.

3) En el artículo 3 del Real Decreto-ley 5/2009, de 24 de abril, de medidas extraordinarias y urgentes para facilitar a las Entidades Locales el saneamiento de deudas pendientes de pago con empresas y autónomos, como requisito para concertar la operación de endeudamiento. La operación de endeudamiento requerirá la aprobación por la Entidad Local de un plan de saneamiento que, por el mismo período de amortización de aquélla, contendrá los compromisos anuales de ingresos y gastos corrientes que, en el ámbito de su autonomía, adquiera, estimados, los primeros, tomando como referencia la liquidación de 2008, con criterios de prudencia de acuerdo con la capacidad real de generación de los mismos, e incrementados, los segundos, en la amortización anual de la operación de endeudamiento regulada en la presente norma y en la del resto de operaciones de endeudamiento existentes con anterioridad, en la forma estipulada en sus respectivos contratos.

El plan incorporará asimismo explicación detallada y cuantificada de las medidas fiscales, de gestión y administrativas.

La relación entre el plan de saneamiento del artículo 3 del Real Decretoley 5/2009 y los planes previstos en la normativa reguladora de las haciendas locales y de estabilidad presupuestaria la encontramos regulada en la D.F. Primera del Real Decreto-ley, debiendo el regulado en esta norma elaborarse, presentarse y evaluarse de forma independiente de los restantes planes que permanecen vigentes.

De forma bastante simplificada los Planes de Saneamiento o Reequilibrio consisten en un análisis de la situación como punto de partida y una proyección para los ejercicios siguientes con las medidas correctoras a adoptar, tanto en materia de ingresos como de gastos. A continuación estudiaremos como la puesta en marcha de la LAULA y LPTCA nos puede ayudar a la selección de esas medidas correctoras. 


\section{ESTRATEGIA DE IMPLEMENTACIÓN DE LA LAULA Y LA LPTCA}

\section{Estrategia de implementación de la LAULA:}

\section{A. Competencias Impropias.}

Dentro del Título I "La Comunidad Política Local" de la LAULA nos encontramos el Capítulo II "Competencias" (artículos 6 a 25). El artículo 6.2 establece que las competencias locales que determina esta Ley tienen la consideración de propias y mínimas, y podrán ser ampliadas por las leyes sectoriales. Lo que nos lleva a la tan traída cuestión de las llamadas "competencias impropias".

Los Ayuntamientos han ofrecido a sus ciudadanos una serie de servicios que no eran competencia obligatoria de estas entidades locales. La mayor parte de estos servicios eran competencias a asumir por las Comunidades Autónomas, en virtud del artículo 148 de la Constitución Española. Sin embargo, los Ayuntamientos, ante una demanda ciudadana insatisfecha, incrementaron progresivamente sus presupuestos, mediante la oferta de estos servicios. Son las llamadas competencias impropias. La decisión pudo ser motivada por la interrelación de tres factores: demanda local insatisfecha, oportunidad política local y predisposición de las Comunidades Autónomas a descentralizar de hecho este gasto, a través de la firma de convenios dotados de financiación insuficiente para la prestación de estos servicios. Esta situación se acentuó en la época de expansión económica, a pesar de la insuficiencia crónica de nuestras Haciendas locales. Pero con la llegada de la crisis económica solo existen dos opciones: o se otorga mayor financiación para seguir ejerciendo estas competencias impropias o deben dejar de prestarse los servicios derivados de éstas.

La FEMP ha calculado que estas competencias impropias cuestan a los ayuntamiento españoles 6.000 millones de euros al año. Estos más de 6.000 millones de euros equivalen a aproximadamente al 30\% de los gastos corrientes de los ayuntamientos.

Bien es verdad que la estructura de presentación de las competencias municipales en la LAULA atribuyendo funciones y materias específicas no debería acentuar este problema y ofrece más garantía que el derecho genérico a intervenir en los asuntos públicos basado en el principio de cercanía al ciudadano. 


\section{B. Servicios e iniciativa económica local.}

El Título II de la LAULA regula los servicios y la iniciativa económica locales (artículos 26 a 49).

Siguiendo a Victoriano Ángel Suárez Rincón ${ }^{4}$, es necesaria una nueva praxis en la gestión local de los servicios públicos para el logro de la eficiencia y la suficiencia económica en la actividad local. Se trata de que la praxis de gestión local se realice bajo un prisma económico y con la utilización de técnicas empresariales. Para lo cual propone cinco líneas de actuación esenciales para esta nueva praxis técnica y política en la gestión local:

1) Modernización de los procesos. Se impone, pues, con mayor necesidad el proceder a una modernización de la estructuras de gestión económica en las Entidades Locales, mediante la adopción de procesos metodológicos y de organización.

2) Incentivar la eficiencia. La inexistencia de un objetivo de maximización del beneficio en la Administración Pública genera una falta de motivación en la consecución de eficiencia económica de la gestión local. Es preciso la implantación de indicadores de gestión que midan el logro de objetivos preestablecidos con los medios económicos y materiales empleados. La estandarización de estos indicadores permitiría el establecimiento de la comparación de eficiencia entre las entidades locales y, en su suma, la implantación de un símil de competitividad.

3) Limitación del principio de maximización de la actividad municipal. El elevado grado alcanzado en los servicios y actividades locales y la incapacidad financiera actual para mantener el alto ritmo de intervencionismo, conduce inexorablemente y hace indispensable la limitación de ese principio de maximización de la actividad municipal.

4) Un fiel sistema de información contable. El hecho de que las anotaciones contables se realice desde el sistema por partida simple y la aplicación informática contable se encargue de realizar automáticamente los asientos por partida doble, es la causa de dos efectos negativos que inciden en la debida representatividad de los informes contables: la falta de contabilización de determinadas operaciones de índole eco-

\footnotetext{
${ }^{4}$ Victoriano Ángel Suárez Rincón. "Suficiencia versus eficiencia económica de las Entidades Locales". auditoriapublica.com
} 
nómico-patrimonial y la escasa especialización contable en el método de partida doble por los contadores municipales, que ha conllevado a que los balances de situación y las cuentas de resultado económico-patrimonial no muestre, en la mayoría de las Administraciones Locales, una fiel imagen de la realidad económica-patrimonial de las mismas. Constituye, pues una necesidad proceder a la adecuación de la información contable con la realidad económica patrimonial y a una correcta llevanza contable de la actividad económica local, como requisito para cumplir los fines de gestión, de control y de análisis y divulgación que tiene asignado en la normativa contable local.

5) Presupuesto por objetivos y programas. El logro de la eficiencia y de la eficacia en las actuaciones del Sector Público requiere disponer de un sistema racional en la toma de decisiones en los procesos de elección de los objetivos públicos a cumplir, en la asignación de recursos y en la programación de la gestión pública. Este sistema no es otro que los presupuestos por objetivos y programas, que utilizando los estudios analíticos de los programas de actuación locales, los escenarios económicos propios y externos y los planes estratégicos y plurianuales, posibilite la asignación y la combinación más racional de los recursos disponibles de tal forma que se logre maximizar los outputs públicos (resultados) y minimizar los inputs (recursos públicos consumidos).

\section{Adaptación de las entidades instrumentales locales.}

La LAULA cambia las modalidades de prestación directa de servicios con entes instrumentales organismos autónomos, entidades públicas empresariales y sociedades mercantiles locales para establecer las modalidades de Agencia pública administrativa local, Agencia pública empresarial local, Agencia especial local, Sociedad mercantil local, Sociedad interlocal y Fundación pública local.

La D.F. $9^{\text {a }}$ da un plazo de tres años desde la entrada en vigor de la ley para que las entidades instrumentales locales se adapten al nuevo régimen jurídico. Plazo que cumple el 23 de julio de 2013.

Este plazo nos da la oportunidad, en esta época de crisis que vivimos, para plantearnos la necesidad de la existencia de cada uno de los entes instrumentales dependientes de nuestras entidades locales, desde el punto de vista tanto de la eficacia como de la eficiencia, sobre todo porque la existencia de los 
mismos conlleva unos costes de gestión duplicados en relación a los servicios centrales de la entidad matriz.

\section{Patrimonio de las entidades locales.}

Regulado en el Título III de la LAULA (artículos 50 a 53).

Puesta de manifiesto la imposibilidad de acudir a operaciones de crédito, ¿deben las entidades locales desprenderse de los bienes inmuebles sin uso para financiar inversiones no productivas? Parece lógico desprenderse de los mismos, pero no es el mejor momento del mercado para vender por lo que posiblemente estemos despatrimonializando a nuestras entidades locales. Quizás debiéramos estudiar darles un uso adecuado y prescindir de los inmuebles alquilados a terceros.

Las Comunidades Autónomas ${ }^{5}$ y algunos Ayuntamientos han enajenado a sociedades propias de mercado bienes patrimoniales para que éstas se endeuden sin que computen como inestabilidad presupuestaria y posteriormente les han alquilado estos bienes para que obtengan recursos con los que pagar los créditos concertados. ¿Es ésta una vía válida en épocas de crisis? Creo que no salvo como medida desesperada para la obtención de liquidez, aunque no demos olvidar que se trata de recursos afectados a gastos de capital.

\footnotetext{
${ }^{5}$ D.A. $6^{\text {a }}$ Ley 12/2010, de 27 de diciembre, de Presupuestos de la Comunidad Autónoma de Andalucía para el ejercicio 2011:

"DISPOSICIÓN ADICIONAL SEXTA. Autorización para operaciones de enajenación de inmuebles, endeudamiento y celebración de contratos de arrendamiento.

Se faculta a la persona titular de la Consejería de Hacienda y Administración Pública para la enajenación directa y a título oneroso a la Sociedad de Gestión, Financiación e Inversión Patrimonial, S.A., a la Empresa Pública de Gestión de Activos, S.A. o a cualquiera otras empresas públicas o privadas, personas fisicas o jurídicas, de los bienes inmuebles, cualquiera que sea su valor, que autorice el Consejo de Gobierno durante el ejercicio 2011, de conformidad con la disposición adicional segunda de la Ley 4/1986, de 5 de mayo, del Patrimonio de la Comunidad Autónoma de Andalucía. Asimismo, se autoriza a las citadas sociedades y empresas públicas para el endeudamiento necesario y, en su caso, para el otorgamiento de garantía de la Junta de Andalucía, para la adquisición de los referidos inmuebles, atendido el valor que se dé a los mismos mediante la oportuna tasación y el de los gastos que la adquisición suponga.

Se autoriza la celebración de contratos de arrendamiento de hasta treinta y cinco años de duración por parte de la Consejería de Hacienda y Administración Pública para la utilización, por parte de las distintas Consejerías de la Administración de la Junta de Andalucía y entidades de Derecho Público vinculadas o dependientes, de los inmuebles adquiridos por la Sociedad de Gestión, Financiación e Inversión Patrimonial, S.A., por la Empresa Pública de Gestión de Activos, S.A. o por cualesquiera otras empresas públicas o privadas, personas fisicas o jurídicas, al amparo de la autorización prevista en el párrafo anterior".
} 


\section{E. Cooperación territorial y Demarcación municipal.}

Los Títulos V "La cooperación territorial" (artículos 60 a 88) y el VI "Demarcación municipal" (artículos 89 a 108) nos llevan a plantearnos la necesidad, para ahorrar costes en nuestras Administraciones Públicas a nivel general, de la fusión e incorporación de municipios. Soy totalmente partidario de estas medidas. Debemos recordar que los grandes municipios como Madrid han ido creciendo absorbiendo a municipios más pequeños que se incorporaban como barrios (ejemplo: Carabanchel entre otros). Los servicios públicos son más eficientes y no es necesario crear ningún ente de cooperación territorial cuya sola existencia conlleva unos costes innecesarios.

Del mismo modo en municipios con una cifra de población muy pequeña que hace que los costes de prestación de los servicios públicos se dispare, además de la necesidad de la existencia de una mínima administración municipal.

Si bien es verdad que se puede producir un gran rechazo ciudadano, por el arraigo histórico que tienen los municipios.

\section{Estrategia de implementación de la LPTCA.}

La Ley 6/2010, de 11 de junio, reguladora de la participación de las entidades locales en los tributos de la Comunidad Autónoma de Andalucía crea un Fondo de Participación de las entidades locales en los tributos de la Comunidad Autónoma de Andalucía, que no es una cesión de la recaudación de tributos de la Comunidad Autónoma, lo que supondría un porcentaje sobre la recaudación de cada tributo. Se trata de un Fondo incondicionado con lo que además de cumplir con los artículos 142 de la Constitución y 192.1 del Estatuto de Autonomía para Andalucía y lo hace con el artículo 9.7 de la Carta Europea de la Autonomía Local que nos dice que: "En la medida de lo posible, las subvenciones concedidas a las Entidades locales no deben ser destinadas a la financiación de proyectos específicos. La concesión de subvenciones no deberá causar perjuicio a la libertad fundamental de la política de las Entidades locales, en su propio ámbito de competencia”.

La creación de este Fondo ha supuesto un incremento importante de los ingresos por transferencias corrientes y al ser incondicionado permitirá financiar con el mismo el conjunto de competencias de los municipios sin afectación a gasto concreto, por lo que, en esta época de crisis la opinión que debemos de tener ha de ser muy favorable ya que contribuye a dotar de suficiencia financiera a nuestras entidades locales. 
El Fondo de Participación de las entidades locales en los tributos de la Comunidad Autónoma de Andalucía toma como modelo el de la participación de los municipios en los tributos del Estado del Texto Refundido de la Ley Reguladora de las Haciendas Locales, se establece una dotación global que variará anualmente según lo haga los Ingresos Tributarios de la Comunidad Autónoma de Andalucía (en adelante los ITA), con entregas a cuenta según la previsión de variación y liquidación definitiva cuando ya se conoce el importe definitivo del Fondo por aplicación de la variación definitiva de los ITA en un año determinado. El reparto del Fondo se realiza en cuatro grupos según población y aplicando una variables dentro de una fórmula general para cada grupo.

En el Anexo I de la Ley encontramos la distribución de los municipios por grupos. Así en el grupo 1 estarán los municipios de menos de 5.000 habitantes, en el grupo 2 de 5.000 a 19.999 habitantes, en el grupo 3 de 20.000 a 49.999 habitantes y en el grupo 4 de 50.000 habitantes o más.

El primer ejercicio de aplicación del Fondo es 2011, con una dotación de 420.000.000 euros y se incrementará en 60.000.000 euros cada uno de los ejercicios 2012, 2013 y 2014 para a partir de dicho año una vez alcanzados los 600.000.000 euros y tomando como base dicho importe se implemente todo el sistema tanto de entregas a cuenta y liquidación definitiva como de variación anual según variación de los ITA.

Los ITA están constituidos, en cada ejercicio, por la recaudación líquida derivada de las siguientes figuras tributarias:

a) Impuesto sobre emisión de gases a la atmósfera.

b) Impuesto sobre vertidos a las aguas litorales.

c) Impuesto sobre depósito de residuos radiactivos.

d) Impuesto sobre depósito de residuos peligrosos.

e) Impuesto sobre Sucesiones y Donaciones.

f) Impuesto sobre Transmisiones Patrimoniales y Actos Jurídicos Documentados.

g) Tasa fiscal sobre los juegos de suerte, envite o azar.

h) Impuesto Especial sobre Determinados Medios de Transporte.

i) Impuesto sobre las Ventas Minoristas de Determinados Hidrocarburos.

La distribución del Fondo entre los cuatro grupos de municipios tiene un factor de corrección a favor de los grupos 1 y 2, que son los de menor población. La dotación del Fondo para el conjunto de municipios pertenecientes a 
cada grupo se obtendrá en cada uno de los ejercicios 2012, 2013 y 2014 de la siguiente manera:

a) Para el conjunto de municipios pertenecientes al grupo 1, la dotación del Fondo será igual a la dotación global del Fondo menos la dotación del mismo asignada a los grupos 2, 3 y 4 según las operaciones descritas en los tres párrafos siguientes.

b) Para el conjunto de municipios pertenecientes al grupo 2, la dotación del Fondo será una cantidad equivalente a la suma de los importes percibidos por los municipios pertenecientes al grupo en 2009 en concepto de Fondo de Nivelación, incrementada dicha suma en el importe que resulte de distribuir la dotación global del Fondo para cada ejercicio minorada en el importe global del Fondo de Nivelación del ejercicio 2009, en función de la población correspondiente a los municipios del citado grupo respecto a la población de los municipios de Andalucía.

c) Para el conjunto de municipios pertenecientes al grupo 3, la dotación del Fondo será una cantidad equivalente a la suma de los importes percibidos por los municipios pertenecientes al grupo en 2009 en concepto de Fondo de Nivelación, incrementada dicha suma en un 95\% del importe que resulte de distribuir la dotación global del Fondo para cada ejercicio minorada en el importe global del Fondo de Nivelación del ejercicio 2009 en función de la población correspondiente a los municipios del citado grupo respecto a la población de los municipios de Andalucía.

d) Para el conjunto de municipios pertenecientes al grupo 4, la dotación del Fondo será una cantidad equivalente a la suma de los importes percibidos por los municipios pertenecientes al grupo en 2009 en concepto de Fondo de Nivelación, incrementada dicha suma en un $90 \%$ del importe que resulte de distribuir la dotación global del Fondo para cada ejercicio minorada en el importe global del Fondo de Nivelación del ejercicio 2009 en función de la población correspondiente a los municipios del citado grupo respecto a la población de los municipios de Andalucía.

Los recursos del Fondo para el conjunto de municipios pertenecientes a cada grupo se distribuyen en función de las variables indicadoras de la necesidad de gasto y del inverso de la capacidad fiscal.

Las variables indicadoras de las necesidades de gasto para cada municipio son: 
a) El importe de las transferencias de financiación del Fondo de Nivelación de los servicios municipales percibido por cada municipio del grupo 1 en el ejercicio 2009.

b) La población relativa de cada municipio con respecto a la población total del conjunto de municipios que pertenecen al mismo grupo.

c) La superficie urbana relativa de cada municipio con respecto a la superficie urbana total del conjunto de municipios que pertenecen al mismo grupo.

d) La dispersión relativa de cada municipio con respecto a la dispersión total del conjunto de municipios que pertenecen al mismo grupo.

La variable indicadora del inverso de la capacidad fiscal es el inverso de la cuota líquida estimada del Impuesto sobre Bienes Inmuebles de naturaleza urbana de cada municipio, en relación con la suma de los inversos de la cuota líquida del Impuesto sobre Bienes Inmuebles de naturaleza urbana del conjunto de municipios que pertenecen al mismo grupo.

Las cuotas líquidas estimadas del Impuesto sobre Bienes Inmuebles de naturaleza urbana se calcularán, para cada municipio, como el resultado de aplicar un tipo medio a la base liquidable del Impuesto sobre Bienes Inmuebles de naturaleza urbana del municipio, siendo dicho tipo medio el cociente entre las cuotas líquidas y las bases liquidables de naturaleza urbana para el conjunto de municipios que pertenecen al mismo grupo.

La dotación del Fondo para el conjunto de municipios pertenecientes al grupo 1 se distribuye entre cada uno de dichos municipios atendiendo a la fórmula general siguiente:

$\mathrm{FPil}=\mathrm{FNi} 1+(\alpha \mathrm{POB} i 1+\beta \mathrm{SUP} i 1+\gamma \mathrm{DIS} i 1+\delta 1 / \mathrm{CF} i 1) \mathrm{x}(\mathrm{FP} 1-\mathrm{FN} 1)$

donde:

$\alpha+\beta+y+\delta=1$

FP1 es la dotación del Fondo para el grupo 1.

FN1 es el importe de la suma de las cantidades percibidas por todos los municipios del grupo 1 en concepto de Fondo de Nivelación en el ejercicio 2009. 
FP il es la participación en el Fondo que corresponde al municipio i del grupo 1 , para $\mathrm{i}=1,2, \ldots, \mathrm{ml}$, siendo $\mathrm{ml}$ el número total de municipios pertenecientes al grupo 1.

FN il es el Fondo de Nivelación del municipio i del grupo 1, correspondiente al ejercicio 2009, para $\mathrm{i}=1,2, \ldots, \mathrm{ml}$, siendo $\mathrm{ml}$ el número total de municipios pertenecientes al grupo 1 .

POB il es el cociente entre la población del municipio i del grupo 1 y la suma de la población para el conjunto de municipios del grupo 1 , para $\mathrm{i}=1,2$," $\mathrm{ml}$, siendo $\mathrm{ml}$ el número total de municipios pertenecientes al grupo 1 .

SUP il es el cociente entre la superficie urbana del municipio i del grupo 1 y la suma de la superficie urbana para el conjunto de municipios del grupo 1 , para $\mathrm{i}=1,2, \ldots, \mathrm{ml}$, siendo $\mathrm{ml}$ el número total de municipios pertenecientes al grupo 1 .

DIS il es el cociente entre el número de entidades singulares del municipio i del grupo 1 y la suma del número de entidades singulares para el conjunto de municipios del grupo 1 , para $\mathrm{i}=1,2, \ldots . \mathrm{m} 1$, siendo $\mathrm{m} 1$ el número total de municipios pertenecientes al grupo 1 .

1/CF il es el cociente entre el inverso de la cuota líquida estimada del Impuesto sobre Bienes Inmuebles de naturaleza urbana del municipio i del grupo 1 y la suma de los inversos de la cuota líquida estimada del Impuesto sobre Bienes Inmuebles de naturaleza urbana para el conjunto de municipios del grupo de población 1 , para $\mathrm{i}=1,2, \ldots, \mathrm{ml}$, siendo $\mathrm{m} 1$ el número total de municipios pertenecientes al grupo 1 .

La dotación del Fondo para el conjunto de municipios pertenecientes a los grupos 2, 3 y 4 se distribuye entre cada uno de los municipios atendiendo a la fórmula general siguiente:

$$
\mathrm{FP}_{\mathrm{ij}}=(\alpha \text { POB } \mathrm{ij}+\beta \mathrm{SUP} i \mathrm{j}+\gamma \text { DIS ij }+\delta 1 / \mathrm{CF} \mathrm{ij}) \mathrm{x}(\mathrm{FPj})
$$

A efectos de las dos fórmulas anteriores, las ponderaciones $\alpha, \beta, \gamma$ y $\delta$ de las variables de necesidad de gasto y del inverso de la capacidad fiscal son las siguientes:

$$
\alpha=0,85 ; \beta=0,06 ; \gamma=0,05 ; \delta=0,04 ;
$$


Esto quiere decir que puesto que no podemos actuar sobre las variables indicadoras de las necesidades de gasto, la posibilidad de actuar sobre la distribución del Fondo se limita a la variable indicadora del inverso de la capacidad fiscal y solo tendría repercusión en el 4 por ciento del mismo. Además, el cálculo favorece a los municipios con base imponible más baja, por lo que un incremento en la base nos perjudicaría.

Como nos dice la exposición de motivos de la Ley:

"Por su parte, en aplicación del principio de corresponsabilidad fiscal, los indicadores de capacidad fiscal pretenden recoger las fundamentales fuentes de ingresos propios de las entidades locales midiendo la «capacidad fiscal normativa» de cada municipio con independencia de las decisiones de política fiscal que en cada uno de ellos se adopten. Además, la configuración del Fondo pretende incentivar que los gobiernos locales no sustituyan sus propios ingresos tributarios por financiación incondicionada procedente de la Comunidad Autónoma". 